ORIGINAL ARTICLE

\title{
Response of bone metabolism related hormones to a single session of strenuous exercise in active elderly subjects
}

\author{
L Maïmoun, D Simar, D Malatesta, C Caillaud, E Peruchon, I Couret, M Rossi, D Mariano-Goulart
}

Br J Sports Med 2005;39:497-502. doi: 10.1136/bjsm.2004.013151

See end of article for authors' affiliations

Correspondence to: Laurent Maïmoun, Centre Propara, Parc

Euromedecine, 263 rue du Caducée, 34195

Montpellier, France;

laurent.maimoun@oreka. com

Accepted 5 October 2004

\begin{abstract}
Objective: To evaluate the effect of strenuous exercise on bone metabolism and related hormones in elderly subjects.

Methods: Twenty one active elderly subjects ( 11 men and 10 women; mean age 73.3 years) showing a mean theoretical $\mathrm{Vo}_{2 \max }$ of $151.4 \%$ participated. Concentrations of plasma ionised calcium (iCa), serum intact parathyroid hormone (iPTH), 25-hydroxyvitamin D (25(OH)D), and 1.25-dihydroxy-vitamin D3 $\left(1.25(\mathrm{OH})_{2} \mathrm{D} 3\right)$, as well as the bone biochemical markers type I collagen C-telopeptide for bone resorption and osteocalcin and bone alkaline phosphatase for bone formation, were analysed before and after a maximal incremental exercise test.

Results: At basal level, iPTH was positively correlated with age $(r=0.56, p<0.01)$ and negatively correlated with 25(OH)D $(r=-0.50 ; p<0.01)$ and $1.25(\mathrm{OH})_{2} \mathrm{D} 3(\mathrm{r}=-0.47 ; \mathrm{p}<0.05)$. Moreover, $25(\mathrm{OH}) \mathrm{D}$ and $1.25(\mathrm{OH})_{2} \mathrm{D} 3$ levels were negatively correlated with age $(r=-0.50, p<0.01$ and $r=-0.53, p<0.01$, respectively). After exercise, $\mathrm{iCa}$ and $25(\mathrm{OH}) \mathrm{D}$ decreased $(p<0.001$ and $p=0.01$, respectively) while iPTH increased $(p<0.001)$. The levels of $1.25(\mathrm{OH})_{2} \mathrm{D} 3$, bone biochemical markers, haematocrit, and haemoglobin were unchanged. The variations in $\mathrm{iCa}$ and $25(\mathrm{OH}) \mathrm{D}$ were not related to age and/or sex. The iPTH variation was directly related to basal iPTH levels $(p<0.01)$ and indirectly related to age.

Conclusions: In active elderly subjects, strenuous exercise disturbed calcium homeostasis and bone related hormones without immediate measurable effect on bone turnover. Although an increase in iPTH could have an anabolic action on bone tissue, our findings from our short term study did not allow us to conclude that such action occurred.
\end{abstract}

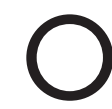
teoporosis, which is a major public health problem, can be defined as a diffuse skeletal disease with reduced bone mass and altered bone micro-architecture as its main structural features. ${ }^{1}$ Both abnormalities result in increased fragility of the skeleton, and hip fracture is the most serious complication with associated high rates of morbidity and mortality. ${ }^{2}$ Osteoporosis is a multifactorial process that depends on several environmental factors, such as dietary calcium deficiency ${ }^{3}$ and genetic influences. ${ }^{4}$

Improving nutritional habits, particularly dietary calcium intake, and increasing the level of physical activity have been suggested as practical strategies for the non-pharmacological prevention of osteoporosis. ${ }^{5}$ Physical exercise has different beneficial effects on the skeleton according to the period of life in which it is undertaken: it optimises peak bone mass in growing children ${ }^{6}$ and maintains bone mass or reduces the bone loss rate in the elderly. ${ }^{7}$ The beneficial effect of physical activity on bone mineral density (BMD) was particularly well demonstrated in power trained athletes engaged in high impact or strengthening exercises, ${ }^{8}$ but such an activity level is not conceivable in fragile elderly subjects. Furthermore, the search for a relationship between physical activity and bone density in osteoporotic patients has not always led to consistent findings. Although most authors have reported the beneficial effects of exercise on bone mass, ${ }^{9}{ }^{10}$ others have not. ${ }^{11}$ These conflicting results may be related to selection differences (age, gender, subject's initial BMD), the explored bone sites, ${ }^{59}$ or the duration and type (intensity, mechanical loading, and so on) of the exercise program. ${ }^{9}$ To optimise the effect of physical activity on bone health, a better understanding of the bone tissue responses to specific mechanical stimuli is therefore needed. More precise definition of the biomechanical specifications, as well as the intensity, duration, and frequency of the exercise to be prescribed, would most likely lead to more efficient prevention of bone loss.

By consensus, BMD is usually measured to estimate bone health and may be the primary indicator of the risk of osteoporotic fractures. ${ }^{12}$ However, although BMD measurements provide a static representation of bone mineral status, they cannot be used to evaluate the slight bone metabolic changes induced by a single episode of physical exercise. Biochemical markers, on the other hand, can be used to assess dynamic changes in bone turnover and appear to be sensitive enough to determine the bone response to a given exercise. Brahm et $a l^{13}$ demonstrated favourable systemic effects of physical exercise on bone metabolism using serum bone markers, while Wallace et $a l^{14}$ showed that endurance exercise transiently activates bone and collagen turnover. In elderly subjects, bone markers are used especially for monitoring treatment for osteoporosis. ${ }^{15}$ Few reports, however, are available concerning the effects of physical exercise on bone markers in a healthy aged population. ${ }^{16}$ Moreover, the immediate effect of exercise on calcium homeostasis and bone turnover has never been evaluated in this population, even though the data obtained from bone marker based

Abbreviations: $1.25(\mathrm{OH})_{2} \mathrm{D} 3,1.25$-dihydroxy-vitamin $\mathrm{D} 3 ; 25(\mathrm{OH}) \mathrm{D}$, 25-hydroxyvitamin D; B-ALP, bone alkaline phosphatase; BMD, bone mineral density; BMI, body mass index; bpm, beats per minute; CTX, type I collagen $\mathrm{C}$-telopeptide; $\mathrm{CV}$, coefficient of variation; $\mathrm{Hb}$,

haemoglobin; Hct, haematocrit; HR, heart rate; $\mathrm{iCa}$, ionised calcium; iPTH, intact parathyroid hormone; IRMA, immunoradiometric assay; OC, osteocalcin; RER, respiratory exchange ratio; RIA, radioimmunoassay; $\mathrm{V}_{\mathrm{CO}_{2}}, \mathrm{CO}_{2}$ output; $\mathrm{VE}$, ventilation; $\mathrm{Vo}_{2}$, oxygen consumption 
investigating methods would provide useful information for the design of therapeutic programs to improve bone health.

The aim of our study was to determine to what extent a single session of brisk walking exercise affected bone metabolism related hormones in active elderly subjects. Normal walking is generally not considered to be a high impact loading activity, but it is the only physical exercise commonly practiced by the elderly. Moreover, we examined whether the response was sex or age dependent, and whether it was likely to provide early indications of the effects of physical exercise (if any) on the bone biochemical markers.

\section{METHODS \\ Subjects}

Twenty one physically active elderly subjects, 11 men and 10 women (mean age 73.3 years, range $60-88$ ) who were free of any limiting orthopaedic conditions, underwent medical screening that included a medical history, a physical examination, and an electrocardiogram. The non-inclusion criteria were medical treatment known to affect bone metabolism, osteoporotic hip or vertebral fractures, cardiovascular disease, diabetes mellitus, smoking, and excessive alcohol intake. Ethical approval was obtained from the local ethics committee and informed consent was given by the subjects.

The subjects were asked to complete a series of questionnaires concerning their medical history and physical activity level. This last was assessed with a questionnaire specifically adapted for the elderly, ${ }^{17}$ with different scores to quantify household, sports, and other physically active leisure time activities, together resulting in a total activity score. The questionnaire provided a method for classifying elderly subjects into categories of high, medium, and low physical activity, with cut off points of 16.5 and 9.4. ${ }^{17}$ Answers to routine queries about known metabolic disorders, current medication, diet, possible vitamin and mineral supplementation, and smoking/alcohol consumption were also collected.

\section{Experimental protocol}

The experiments were carried out in two sessions separated by at least 4 days and never more than 7 days. During the first session, the subjects' preferred walking speed was determined. The second session was devoted to a maximal incremental exercise test.

\section{Preferred walking speed determination}

The subjects began treadmill walking at the lowest familiarisation speed $\left(0.67 \mathrm{~m} \mathrm{~s}^{-1}\right)$, which was then slowly increased until each subject subjectively identified his or her preferred walking speed. This speed was maintained for $1 \mathrm{~min}$ and was then modified slightly. The subject was again asked to evaluate the speed and adjustments were made according to the subject's directives. This procedure was repeated starting with the highest familiarisation speed $\left(1.56 \mathrm{~m} \mathrm{~s}^{-1}\right)$ and gradually reducing to the preferred speed. The final preferred walking speed was considered to be the mean of the two speeds selected by the subject during both the increasing and decreasing speed trials. ${ }^{17}{ }^{18}$ During this session and the exercise test, the subjects were secured continuously by a cross-belt fixed to the handrails in such a way that arm swing was not impeded.

\section{Maximal incremental exercise test}

The subjects arrived at the laboratory at 8.00 a.m. after a $12 \mathrm{~h}$ overnight fast. At 8.30 a.m., a resting blood sample was drawn for analysis of biochemical parameters. The subjects then performed a maximal incremental exercise test at the individually determined preferred walking speed as previously described. ${ }^{18}$ After a 3 min standing rest period, they were asked to walk for $5 \mathrm{~min}$ at $0 \%$ grade for warm up. The grade was then increased by $1-2 \%$ each minute until exhaustion, resulting in a test duration of between 8 and $12 \mathrm{~min}$. During the test, oxygen consumption $\left(\mathrm{VO}_{2}\right), \mathrm{CO}_{2}$ output $\left(\mathrm{VCO}_{2}\right)$, and ventilation (VE) were analysed breath by breath using an on line system (LE 200 CE, Jaeger, Hoechberg, Germany) and averaged every $20 \mathrm{~s}$. Cardiac activity was continuously monitored using a 12 lead electrocardiogram (Oxycon Pro, Jaeger). Theoretical $\mathrm{Vo}_{2}$ maximum $\left(\mathrm{Vo}_{2 \max }\right.$ th) values were obtained using reference equations specifically developed in older adults aged 5586 years during a treadmill maximal exercise test, according to age and sex. ${ }^{19}$ Different equations were thus specifically developed for men $\left(\mathrm{Vo}_{2 \max }\right.$ th $\left(\mathrm{ml} \mathrm{kg}^{-1} \mathrm{~min}^{-1}\right)=44.23-$ $0.31 \times$ age $)$ and women $\left(\mathrm{Vo}_{2 \max }\right.$ th $\left.\mathrm{ml} \mathrm{kg}^{-1} \mathrm{~min}^{-1}\right)=$ 36.63-0.25 xage. $\mathrm{Vo}_{2 \max }$ was considered to be attained if the subject reported a feeling of fatigue and if one of the following criteria was reached: (a) a plateau in oxygen uptake concurrent with continuing increase in exercise intensity or (b) respiratory exchange ratio (RER) greater than 1.0 and heart rate (HR) within 5 beats per minute (bpm) of the theoretical age specific maximal $\mathrm{HR}=$ $(-0.84 \times$ age $)+217.31$ for men and $\mathrm{HR}=(-0.91 \times$ age $)+221.7$ for women. ${ }^{19}$

\section{Sample collection}

Blood samples $(20 \mathrm{ml})$ were collected in sterile chilled tubes, at rest and just after the maximal incremental exercise test. The samples were allowed to clot at room temperature and were then centrifuged at $2500 \mathrm{rpm}$ for $10 \mathrm{~min}$ at $4^{\circ} \mathrm{C}$. Serum samples were stored at $-80^{\circ} \mathrm{C}$ until analysis.

\section{Biochemical assays}

All samples were run in duplicate and, to reduce inter-assay variation, all the serum samples were analysed in a single session.

\section{Calcium homeostasis}

Ionised serum calcium (iCa) was measured by an ionselective electrode (BGE, Electrolytes Instrumentation Laboratory, Lexington, MA). Intact parathyroid hormone (1-84) (iPTH) was measured by an immunoradiometric assay (IRMA) (N-tact PTH SP, DiaSorin, Stillwater, MN). The intraand inter-assay coefficients of variation (CVs) were $3.6 \%$ and $3.4 \%$, respectively. The sensitivity of the test was $0.7 \mathrm{pg} \mathrm{ml}^{-1}$ with no cross-reaction with human PTH fragments. The reference range for iPTH in our laboratory was 10$55 \mathrm{pg} \mathrm{ml}^{-1}$. The level of 25-hydroxyvitamin D (25(OH)D) was measured by radioimmunoassay (RIA) (25-hydroxyvitamin D RIA kit, Nichols Institute Diagnostics, Paris, France). The intra- and inter-assay CVs were $5 \%$ and $8.1 \%$, respectively. Assay sensitivity was $<1.2 \mathrm{ng} \mathrm{ml}^{-1}$. Serum 1.25 dihydroxy-vitamin $\mathrm{D} 3\left(1.25(\mathrm{OH})_{2} \mathrm{D} 3\right)$ was measured by RIA (1.25-dihydroxyvitamin D RIA kit, Nichols Institute Diagnostics). The sensitivity of the assay was $2.1 \mathrm{pg} \mathrm{ml}^{-1}$. The intra- and inter-assay CVs were $5 \%$ and $10.8 \%$, respectively. The reference range for $1.25(\mathrm{OH})_{2} \mathrm{D} 3$ in our laboratory was 20-66 $\mathrm{pg} \mathrm{ml}^{-1}$.

\section{Bone biochemical markers} Markers of bone formation

Serum osteocalcin (OC) was measured by IRMA assay (ElsaOST-NAT, CIS Biointernational, Gif/Yvette, France). The intra- and inter-assay CVs were below $5 \%$ and the sensitivity was $0.3 \mathrm{ng} \mathrm{ml}^{-1}$. The reference range for serum OC in our laboratory was 5-20 $\mathrm{ng} \mathrm{ml}^{-1}$. Serum bone alkaline phosphatase (B-ALP) was measured by IRMA assay (Tandem-R Ostase, Hybritec, San Diego, CA). The sensitivity of the assay was $0.2 \mathrm{ng} \mathrm{ml}^{-1}$, and the intra- and inter-assay CVs were less 
Table 1 Characteristics of the study participants

\begin{tabular}{|c|c|c|}
\hline Variables & Mean (SD) & Range \\
\hline Age (year) & $73.3(9.1)$ & $60-88$ \\
\hline Weight (kg) & $65.8(13.2)$ & $47-89$ \\
\hline Height $(\mathrm{cm})$ & $166.3(9.2)$ & $152-180$ \\
\hline $\mathrm{BMI}\left(\mathrm{kg} \mathrm{m}^{-2}\right)$ & $23.6(2.9)$ & $18.7-31.1$ \\
\hline$V_{o_{2 \max }}\left(1 \min ^{-1}\right)$ & $2.06(0.77)$ & $1.16-3.49$ \\
\hline $\mathrm{Vo}_{2 \max }\left(\mathrm{ml} \min ^{-1} \mathrm{~kg}^{-1}\right)$ & $30.5(7.1)$ & $18.3-45.1$ \\
\hline $\mathrm{Vo}_{2 \max }$ th $\left(\mathrm{ml} \mathrm{min} \operatorname{mog}^{-1} \mathrm{~kg}^{-1}\right)$ & $20.1(3.5)$ & $14.6-25.6$ \\
\hline$\% \mathrm{Vo}_{2 \max }$ th $\left(\mathrm{ml} \mathrm{min}-1 \mathrm{~kg}^{-1}\right)$ & $151.4(12.5)$ & $125-195$ \\
\hline Exercise duration (min) & $9.9(1.4)$ & $8-13$ \\
\hline Maximal slope (\%) & $15(5)$ & $5-24$ \\
\hline Physical activity score & $20.1(7.1)$ & $11.9-38.6$ \\
\hline
\end{tabular}

Data are presented as means (SD). $\mathrm{BMI}$, body mass index; $\mathrm{V}_{2 \text { max }}$ maximal $\mathrm{O}_{2}$ uptake. $\mathrm{Vo}_{2 \text { max }}$ th, theoretical maximal $\mathrm{O}_{2}$ uptake.

than $7 \%$ and $9 \%$, respectively. The reference range for serum $\mathrm{B}-\mathrm{ALP}$ in our laboratory was 4-15 $\mathrm{ng} \mathrm{ml}^{-1}$.

\section{Marker of bone resorption}

Serum type I-C telopeptide breakdown products (CTX) were measured by ELISA (CrossLaps ELISA, Osteometer, Rodovre, Denmark). The intra- and inter-assay CVs were less than $5.7 \%$ and $9.4 \%$, respectively, and the detection limit was $0.5 \mu \mathrm{g} \mathrm{l}^{-1}$. The reference range for CTX was $<5500 \mathrm{pmol} \mathrm{l}^{-1}$ (manufacturer's specification).

\section{Other parameters}

Haematocrit $(\mathrm{Hct})$ and haemoglobin $(\mathrm{Hb})$ were determined by routine laboratory tests at rest and during exercise to ensure that measurements of metabolite and hormone concentrations were not influenced by changes in plasma volume.

\section{Statistical analysis}

All data are expressed as means (SD). The Gaussian distribution of variables was assessed by the Shapiro-Wilk statistical test. The differences between baseline pre-exercise and post-exercise data were assessed with Student's paired $t$ test. When the $t$ test was significant, the effect of independent variables such as sex and age was assessed by ANCOVA. When the ANCOVA test revealed that the independent variable significantly contributed to the outcome, Pearson correlation was performed to examine the degree of association between the variables. A level of $p<0.05$ was considered significant. SAS software, version 8.2 (SAS Institute, Cary, NC) was used for statistical analysis.

\section{RESULTS}

The anthropometric data and the parameters of physical fitness of the participants are shown in table $1 . \mathrm{Vo}_{2 \max }$ represented $150 \%$ of the predicted value, highlighting the high physical fitness of our population. According to the physical activity questionnaire previously established, ${ }^{17}$ all subjects were classified in the medium or high physical activity categories.

\section{Response of biochemical parameters to exercise}

The variations in the parameters of calcium homeostasis are shown in table 2. The concentrations of iCa and 25(OH)D were decreased significantly after exercise $(p<0.001$ and $p=0.01$, respectively) compared with pre-exercise measurement. The values of $1.25(\mathrm{OH})_{2} \mathrm{D} 3$, Hct, and $\mathrm{Hb}$ were unchanged $(p>0.05)$. The concentrations of iPTH were significantly increased after exercise $(\mathrm{p}<0.001)$.

The values of the post-exercise bone biochemical markers (CTX, OC, B-ALP) were unchanged compared with preexercise values (table 3 ).

\section{Basal levels of hormones and bone biochemical markers}

All basal hormonal and bone biochemical markers were found to be within the normal ranges (tables 2 and 3). After stratification for gender, there were no significant differences between males and females.

\section{Relationships between age, anthropometric data, and biochemical parameters at baseline}

Table 4 shows the different relationships between age, body mass index (BMI), and the various biochemical parameters at baseline. Age was positively correlated with iPTH $(\mathrm{p}<0.0 \mathrm{l}$, $\mathrm{r}=0.56) \quad(\mathrm{fig} \mathrm{l})$ and negatively correlated with $25(\mathrm{OH}) \mathrm{D}$ $(\mathrm{p}<0.01, \mathrm{r}=-0.5 \mathrm{l})$ and $1.25(\mathrm{OH})_{2} \mathrm{D} 3(\mathrm{p}<0.01, \mathrm{p}=-0.53)$. A negative relationship was found between iPTH and $25(\mathrm{OH}) \mathrm{D} \quad(\mathrm{p}<0.01, \quad \mathrm{r}=-0.51), \quad 1.25(\mathrm{OH})_{2} \mathrm{D} 3 \quad(\mathrm{p}<0.05$, $\mathrm{r}=-0.47)$, and BMI $(\mathrm{p}<0.05, \mathrm{r}=-0.43)$. Correlations were also found between markers at baseline (OC $v$ B-ALP: $\mathrm{p}<0.001, \mathrm{r}=0.76$; OC $v$ CTX: $\mathrm{p}<0.01, \mathrm{r}=0.82$; B-ALP $v$ CTX: $p<0.01, r=0.75$ ). There were no correlations between markers of bone turnover and age, anthropometric data (weight, height, $\mathrm{BMI})$, parameters of physical fitness $\left(\mathrm{Vo}_{2 \max }\right.$ and $\mathrm{Vo}_{2 \max } / \mathrm{kg}$ ), or physical activity score.

\section{Effects of age and sex on the variation in biochemical parameters during exercise}

The variations $(\Delta)$ in iCa and $25(\mathrm{OH}) \mathrm{D}$ were not related to age or sex. A negative correlation $(\mathrm{r}=-0.46, \mathrm{p}=0.035)$ was found between $\triangle \mathrm{iPTH}$ and age. However, since we found that basal iPTH levels were also correlated with age $(r=0.56$, $\mathrm{p}<0.01$ ) (table 4 ), a stepwise linear regression analysis was performed to determine the contribution of possible independent variables (age and basal iPTH) to $\triangle \mathrm{iPTH}$. In fact, only basal iPTH levels $(\mathrm{p}<0.01)$ were independently related to $\triangle \mathrm{iPTH}$.

\section{DISCUSSION}

To our knowledge, this investigation is the first to examine the effects of a single session of high intensity physical exercise on the parameters of calcium homeostasis and the

Table 2 Parameters of calcium homeostasis before and after exercise

\begin{tabular}{|c|c|c|c|c|c|}
\hline Biochemical parameters & Pre-exercise & Post-exercise & $\% \Delta$ & $p$ value & Normal range \\
\hline \multicolumn{6}{|l|}{ Calcium homeostasis } \\
\hline iCa $\left(\mathrm{mmol} \mathrm{I}^{-1}\right)$ & $1.185(0.027)$ & $1.150(0.034)$ & -3 & $<0.001$ & $1.10-1.25$ \\
\hline $25(\mathrm{OH}) \mathrm{D}\left(\mathrm{pg} \mathrm{m} \mathrm{l}^{-1}\right)$ & 23.4 (11.2) & $21(9.3)$ & -10.3 & 0.013 & $16-28$ \\
\hline $1.25(\mathrm{OH})_{2} \mathrm{D} 3\left(\mathrm{pg} \mathrm{m}^{-1}\right)$ & $46(12.5)$ & $46.1(12.9)$ & 0.2 & 0.900 & $20-66$ \\
\hline iPTH $\left(p g \mathrm{ml}^{-1}\right.$ ) & $28.9(9.7)$ & $36.2(11.8)$ & 25 & $<0.001$ & $10-55$ \\
\hline \multicolumn{6}{|l|}{ Other parameters } \\
\hline Hct $(\%)$ & $43.1(3.7)$ & $43.4(3.6)$ & 0.7 & 0.850 & $39-54$ \\
\hline $\mathrm{Hb}\left(\mathrm{g} \mathrm{dl^{-1 }}\right)$ & $14(1.2)$ & $14(1.1)$ & 0 & 0.958 & 13-18 \\
\hline
\end{tabular}

Data are expressed as means (SD). 1.25(OH) 2 D3, 1.25-dihydroxy-vitamin D3; 25(OH)D, 25-hydroxyvitamin D; Hb, haemoglobin; Hct, haematocrit; iCa, ionised calcium; iPTH, intact parathyroid hormone; $\% \Delta$, per cent change from pre- to post-exercise. 
Table 3 Biochemical markers of bone turnover before and after exercise

\begin{tabular}{|c|c|c|c|c|}
\hline Biochemical parameters & Pre-exercise & Post-exercise & p value & Normal range \\
\hline \multicolumn{5}{|l|}{ Bone resorption marker } \\
\hline CTX (pmol I-1) & $5998(3045)$ & $5959(2866)$ & 0.945 & $<5500$ \\
\hline \multicolumn{5}{|l|}{ Bone formation markers } \\
\hline $\mathrm{OC}\left(\mathrm{ng} \mathrm{ml^{-1 }}\right)$ & $12.7(5.5)$ & $12.5(5.3)$ & 0.627 & $5-20$ \\
\hline$B-A L P\left(n g m^{-1}\right)$ & $13.1(4.8)$ & $13.2(4.7)$ & 0.606 & $4-16$ \\
\hline
\end{tabular}

bone biochemical markers in a large elderly population. The main findings were that in elderly physically active subjects: (a) strenuous exercise induced a decrease in iCa and $25(\mathrm{OH}) \mathrm{D}$ concentrations associated with a concomitant increase in iPTH concentration; (b) the variations in these parameters, with the exception of iPTH, were independent of sex and age; and (c) no modification concerning bone turnover, as evaluated by bone biochemical markers, was observed.

\section{Basal calcium homeostasis and bone remodelling}

At baseline, the major factor found to influence hormonal values was age. A relative consensus concerning the increase in serum iPTH with age in the general sedentary population has emerged from the literature, ${ }^{20}$ probably related to vitamin D status. ${ }^{22}$ The similar finding in our study suggests that maintaining a high level of physical activity is not sufficient to compensate for the hormonal profile alteration related to age. Indeed, in our study, an inverse relationship was found between the basal $25(\mathrm{OH}) \mathrm{D}, 1.25(\mathrm{OH})_{2} \mathrm{D} 3$, and iPTH levels. The gradual reduction in $1.25(\mathrm{OH})_{2} \mathrm{D} 3$ production with advancing age seems to be multifactorial and due to a reduction in $1 \alpha$-hydroxylase synthesis associated with the reduced sensitivity of this enzyme to $\mathrm{PTH}^{23}$ a reduced capacity of the skin to produce vitamin D, and lack of exposure to sunlight. ${ }^{24}$ In agreement with the majority of studies, we found no relationship between serum iCa and age. ${ }^{23}$ Moreover, no gender related difference in calciotropic hormonal status or bone turnover was found.

\section{Response of calcium homeostasis to strenuous exercise}

The study showed that a brief incremental exercise test induced a significant variation in the parameters of calcium homeostasis. The rise in serum iPTH level may directly reflect the decrease in serum iCa level, the main regulating factor of PTH secretion. Brent et al ${ }^{25}$ found a strong relationship between extracellular iCa concentration and PTH secretion. This relationship was represented by an inverse sigmoidal curve, suggesting that a slight modification in iCa concentration induces large reciprocal changes in serum PTH. The net changes in these parameters cannot be attributed to haemoconcentration, since no variation in $\mathrm{Hct}$ or $\mathrm{Hb}$ was observed. It is more probable that the metabolic acidosis induced by strenuous exercise was the main factor inducing the calcium metabolism disturbance. Ashisawa et al ${ }^{26}$ reported an increase in urinary calcium excretion after a single bout of resistance exercise through a decrease in renal calcium reabsorption. These alterations were not accompanied by an increase in osteoclast activity. The imbalance between urinary Ca excretion and Ca release from bone may induce a net decrease in serum iCa level. In addition, Lopez et $a l^{27}$ demonstrated that acidosis may also have a direct effect on the increase in PTH secretion independently of calcium level.

The findings reported in the literature concerning the effect of physical activity on PTH and iCa values are conflicting and the degree of variation might reflect differences in the intensity and duration of the exercise. Our results were, nevertheless, in agreement with those of Bouassida et al ${ }^{28}$ who found a decrease in iCa levels and a rise in PTH levels in young subjects during continuous exercise at 70 and $80 \%$ of $\mathrm{Vo}_{2 \text { max }}$. These findings were also observed by Nishiyama et $a l^{29}$ in athletic and non-athletic young men after short and moderately intense exercise. In contrast, Kristoffersson et al ${ }^{30}$ found increased iCa levels after short term maximal work, without significant changes in the serum PTH levels. PTH has been shown to act directly on osteoblasts, whereas its action on osteoclasts is mediated by local factors. ${ }^{31}$ Animal experiments have demonstrated that intermittent administration of PTH increased bone mass and improved trabecular bone microarchitecture, whereas continuous administration by infusion at the same mean rate leads to a net loss of bone mass and altered bone structure. ${ }^{32}$ In accordance with these experimental results, a therapeutic protocol with daily injections of PTH produced the largest gain in trabecular bone mass and reduced the risk of fracture in osteoporotic patients. ${ }^{33}$ Although our results seem to lend support to these findings, the small iPTH variation and the short duration of our study make it difficult to interpret the increase in iPTH during physical exercise as a potential factor to improve bone health. The physiological and clinical significance of the iPTH variation related to strenuous exercise thus remains to be determined.

Table 4 Pearson correlation coefficient of the relationships between age, BMl, and basal biochemical parameter levels

\begin{tabular}{|c|c|c|c|c|c|c|c|c|}
\hline Parameter & BMI & $\mathrm{iCa}$ & 25(OH)D & $1.25(\mathrm{OH})_{2} \mathrm{D} 3$ & iPTH & $O C$ & B-ALP & СТX \\
\hline $\begin{array}{l}\text { Age } \\
\text { BMI } \\
\text { iCa } \\
25(\mathrm{OH}) \mathrm{D} \\
1.25(\mathrm{OH})_{2} \mathrm{D} 3 \\
\text { iPTH } \\
\mathrm{OC} \\
\text { B-ALP }\end{array}$ & -0.378 & $\begin{array}{r}-0.165 \\
0.037\end{array}$ & $\begin{array}{c}-0.504^{\star *} \\
0.075 \\
0.175\end{array}$ & $\begin{array}{l}-0.533^{\star *} \\
0.154 \\
0.263 \\
0.585^{\star *}\end{array}$ & 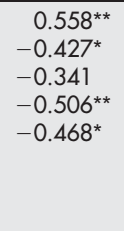 & $\begin{array}{c}0.036 \\
-0.128 \\
0.273 \\
-0.410^{*} \\
-0.154 \\
0.136\end{array}$ & $\begin{array}{r}0.055 \\
-0.073 \\
0.281 \\
-0.364 \\
-0.238 \\
0.148 \\
0.755^{* * *}\end{array}$ & $\begin{array}{r}0.196 \\
-0.344 \\
0.345 \\
-0.584 \\
0.342 \\
0.075 \\
0.821^{* *} \\
0.750^{* *}\end{array}$ \\
\hline
\end{tabular}

B-ALP, bone alkaline phosphatase; BMI, body mass index; CTX, type I collagen C-telopeptide; iCa, ionised calcium; iPTH, intact parathyroid hormone; OC, B-ALP, bone
osteocalcin.

${ }^{*} \mathrm{p}<0.05 ;{ }^{* *} \mathrm{p}<0.01 ;{ }^{* * *} \mathrm{p}<0.001$. 


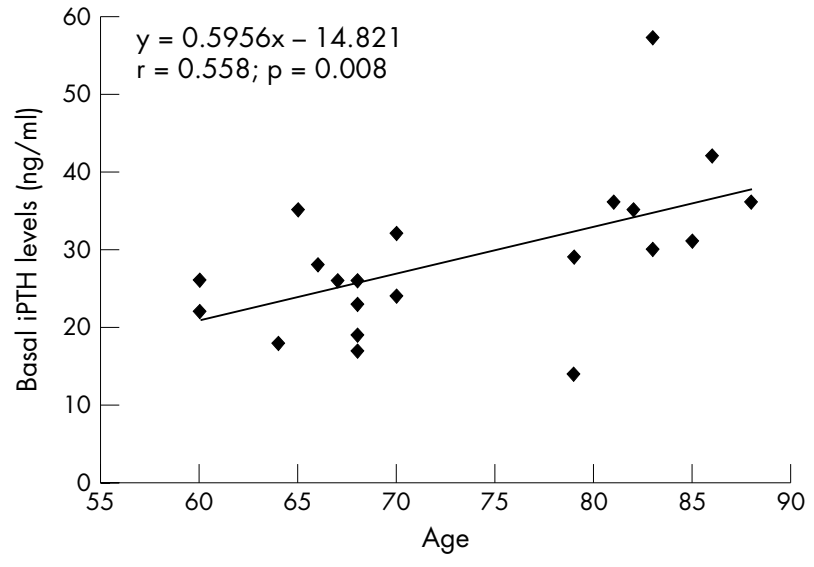

Figure 1 Relationship between age and basal iPTH levels. iPTH, intact parathyroid hormone.

We were unable to determine precisely why the $25(\mathrm{OH}) \mathrm{D}$ level decreased during exercise. It is probable that the increase in iPTH stimulates the kidney production of $1.25(\mathrm{OH})_{2} \mathrm{D} 3$, the most biologically active metabolite of vitamin $\mathrm{D}$ from the precursor $25(\mathrm{OH}) \mathrm{D}$. However, as no variation in $1.25(\mathrm{OH})_{2} \mathrm{D} 3$ was observed, this assumption remains purely speculative and we cannot rule out the possibility that the change in $25(\mathrm{OH}) \mathrm{D}$ levels resulted from a modification in metabolic clearance or degradation.

\section{Response of bone markers to strenuous exercise}

Bone biochemical markers provide a new way to examine the response of bone cells to exercise. Nevertheless, we could not show any significant changes in either serum CTX, which indicates resorption activity, ${ }^{34}$ or serum B-ALP and serum OC, which are considered to reflect newly synthesised bone. ${ }^{35}{ }^{36}$ It is widely acknowledged that long term physical activity with high mechanical loading produces an increase in bone mass, especially at the load bearing bone sites. ${ }^{37}{ }^{38}$ In our experiment, specific physical exercise did not induce any variation in bone biochemical markers, probably because the ground reaction forces generated by brisk walking, that is, approximately 1.1 times body weight, ${ }^{39}$ were insufficient to produce an immediate measurable bone response. Our results were, nevertheless, in accordance with the majority of studies that have investigated the immediate response of bone markers to short and intense or moderate exercise bouts. ${ }^{30}{ }^{40-42}$ Therefore, the relatively short duration of exercise (range 8-13 min), as well as the short time of post-exercise investigation, ${ }^{40}{ }^{41}$ could also explain why no significant bone marker response was observed. Moreover, it seems probable that the bone tissue of our elderly population had become less responsive to exercise. ${ }^{43}$ This was confirmed by Wallace et al ${ }^{14}$ who stated that age is probably a negative determinant of the bone marker response to exercise. However, given the complexity of the bone marker response to physical exercise, these results should be cautiously interpreted. Further investigations of the effects of some of the physical activity related factors, such as clearance or/and release of bone markers, must be carried out.

\section{CONCLUSION}

In active elderly subjects, calcium homeostasis and bone metabolism related hormones were noticeably modified after a single session of strenuous physical exercise. These modifications were mainly characterised by a decrease in iCa and an increase in iPTH levels. Although a transitional increase in iPTH level may have a potential anabolic effect on
What is already known on this topic

Although bone mineral density measurements provide a static representation of bone mineral status, they cannot be used to evaluate the slight bone metabolic changes induced by a single episode of physical exercise.

\section{What this study adds}

In active elderly subjects, calcium homeostasis and bone metabolism related hormones were noticeably modified after a single session of strenuous physical exercise.

bone health, the specific iPTH variation observed after short duration exercise did not allow us to draw a definitive conclusion. Further investigations are required to elucidate the physiological and clinical significance of the observed endocrine modifications. Finally, no measurable effect on bone turnover could be demonstrated immediately after strenuous physical exercise.

\section{ACKNOWLEDGEMENTS}

We are indebted to Dr Dores (Service de Biochimie), Professor C Sultan (Service d'Hormonologie du Développement et de la Reproduction), and the staff of the Laboratoire de Physiologie des Interactions UPRES EA 701, CHU Arnaud de Villeneuve, and the Service de Médecine Nucléaire, CHU Lapeyronie, for excellent technical assistance; and to Dr Regis Verdier and Dr Eric Barbotte for statistical analysis (Département d'Information Médicale).

\section{Authors' affiliations}

D Simar, C Caillaud, Laboratoire Sport Performance Santé UPRES EA 2991, Faculté des Sciences du Sport, Montpellier, France

L Maïmoun, D Malatesta, Laboratoire de Physiologie des Interactions

UPRES EA 701, CHU Arnaud de Villeneuve, Montpellier, France

E Peruchon, INSERM, Montpellier, France

L Maïmoun, I Couret, M Rossi, D Mariano-Goulart, Service de

Médecine Nucléaire, CHU Lapeyronie, Montpellier, France

Competing interests: none declared

\section{REFERENCES}

1 Consensus Development Conference. Diagnosis, prophylaxis and treatment of osteoporosis. Am J Med 1993;94:646-50.

2 Cooper C, Atkinson EJ, Jacobsen SJ, et al. Population-based study of survival following osteoporotic fractures. Am J Epidemiol 1993;137:1001-5.

3 Heanay RP, Gallagher JC, Johnsson CC, et al. Calcium nutrition and bone health in the elderly. Am J Clin Nutr 1982;36:986-1013.

4 Fox KM, Cummings SR, Threets K. Family history and risk of osteoporotic fracture. J Bone Miner Res 1994;9(Suppl 1):S153.

5 Nguyen TV, Center JR, Eisman JA. Osteoporosis in elderly men and women: effects of dietary calcium, physical activity, and body mass index. J Bone Miner Res 2000;15:322-31.

6 Bailey DA, Mc Kay HA, Mirwald RL, et al. The University of Saskatchewan bone mineral accrual study: a six year longitudinal study of the relationship of physical activity to bone mineral accrual in growing children. J Bone Miner Res 1999; 14:1672-9.

7 Lane NE, Bloch DA, Hubert HB, et al. Running, osteoarthritis and bone density: initial 2-year longitudinal study. Am J Med 1990;88:452-9.

8 Creighton DL, Morgan AL, Boardley D, et al. Weight-bearing exercise and markers of bone turnover in female athletes. J Appl Physiol 2001;90:565-70.

9 Kerr D, Morton A, Dick I, et al. Exercise effects on bone mass in postmenopausal women are site-specific and load-dependent. J Bone Miner Res 1996;11:218-25.

10 Ryan AS, Ivey FM, Hurlbut DE, et al. Regional bone mineral density after resistive training in young and older men and women. Scand J Med Sci Sports 2004; 14:16-23.

11 Prince RL, Smith M, Dick IM, et al. Prevention of post-menopausal osteoporosis. A comparative study of exercise, calcium supplementation, and hormone-replacement therapy. N Engl J Med 1991;325:1189-95.

12 Melton LJ, Atkinson EJ, O'Fallon $M$, et al. Long-term fracture prediction by bone mineral assessed at different skeletal sites. J Bone Miner Res 1993;8:1227-33 
13 Brahm H, Piehl-Aulin K, Liunghall S. Bone metabolism during exercise and recovery: the influence of plasma volume and physical fitness. Calcif Tissue Int 1997;61:192-8.

14 Wallace JD, Cuneo RC, Lundberg PA, et al. Responses of markers of bone and collagen turnover to exercise, growth hormone $(\mathrm{GH})$ administration, and $\mathrm{GH}$ withdrawal in trained adult males. J Clin Endocrinol Metab 2000;85: 124-33.

15 Harris ET, Gertz BJ, Genant HK, et al. The effect of short term treatment with alendronate on vertebral density and biochemical markers of bone remodelling in early postmenopausal women. J Clin Endocrinol Metab 1993;76:1399-403.

16 Sartorio A, Lafortuna C, Capodaglio P, et al. Effects of a 16 week progressive high-intensity strength training (HIST) on indexes of bone turnover in men over 65 years: a randomised controlled study. J Endocrinol Invest 2001;24:882-6.

17 Voorrips LE, Ravelli AC, Dongelmans PC, et al. A physical activity questionnaire for the elderly. Med Sci Sports Exerc 1991:23:974-9.

18 Malatesta D, Simar D, Dauvillier Y, et al. Energy cost of walking and gait instability in healthy 65- and 80-year-olds. J Appl Physiol 2003;95:2248-56.

19 Paterson DH, Cunningham DA, Koval JJ, et al. Aerobic fitness in a population of independently living men and women aged 55-86 years. Med Sci Sports Exerc 1999:31:1813-20.

20 Endres DB, Morgan CH, Garry PJ, et al. Age-related changes in serum immunoreactive parathyroid hormone and its biological action in healthy men and women. J Clin Endocrinol Metab 1987:65:724-31.

21 Jorde J, Bonaa KH, Sundsfiord J. Population-based study on serum ionised calcium, serum parathyroid hormone, and blood pressure. The Tromso study. Eur J Endocrinol 1999;141:350-7.

22 Ledger GA, Burrit MF, Kao PC, et al. Abnormalities of parathyroid hormone secretion in elderly women that are reversible by short term therapy with 1,25dihydroxy-vitamin $\mathrm{D}_{3}$. J Clin Endocrinol Metab 1994;79:211-6.

23 Riggs BL, Hamstra A, Deluca HF. Assessment of 25-hydroxyvitamin D 1a hydroxylase reserve in postmenopausal osteoporosis by administration of parathyroid extract. J Clin Endocrinol Metab 1981;53:833-5.

24 Van der Wielen RP, Lowik MR, van den Berg H, et al. Serum vitamin D concentrations among elderly people in Europe. Lancet 1995;346:207-10.

25 Brent GA, Leboff MS, Seely EW, et al. Relation between the concentration and rate of change of calcium and serum intact parathyroid hormone levels in normal humans. J Clin Endocrinol Metab 1988;67:944-50.

26 Ashisawa N, Fujimura R, Tokuyama K, et al. A bout of resistance exercises increases urinary calcium independently of osteoclastic activation in men. J Appl Physiol 1997;83:1 159-63.

27 Lopez I, Aguilera-Tejero E, Felsenfeld AJ, et al. Direct effect of acute metabolic and respiratory acidosis on parathyroid hormone secretion in the dog. J Bone Miner Res 2002:17:1691-700.

28 Bouassida A, Zalleg D, Zaouali Ajina M, et al. Parathyroid hormone concentrations during and after two periods of high intensity exercise with and without an intervening recovery period. Eur J Appl Physio 2002;88:339-44.
29 Nishiyama S, Tomoeda S, Ohta T, et al. Differences in basal and postexercise osteocalcin levels in athletic and nonathletic humans. Calcif Tissue Int 1988;43:150-4.

30 Kristoffersson A, Hultdin J, Holmlund I, et al. Effects of short-term maximal work on plasma calcium, parathyroid hormone, osteocalcin and biochemical markers of collagen metabolism. Int J Sports Med 1995; 16:145-9.

31 Mac Sheehy PMJ, Chambers TJ. Osteoblast-like cells in the presence of parathyroid hormone release soluble factor that stimulates osteoclastic bone resorption. Endocrinology 1986;119:1654-9.

32 Tam CS, Heersche JN, Murray TM, et al. Parathyroid hormone stimulates the bone opposition rate independently of its resorptive action: differential effects of intermittent and continuous administration. Endocrinology 1982;110:506-12.

33 Neer RM, Arnaud CD, Zanchetta JR, et al. Effect of parathyroid hormone (134 ) on fractures and bone mineral density in postmenopausal women with osteoporosis. N Engl J Med 2001;344:1434-41.

34 Bonde $M$, Qvist $P$, Fledelius $C$, et al. Immunoassay for quantifying type I collagen degradation products in urine evaluated. Clin Chem 1994;40:2022-5.

35 Garnero P, Delmas PD. Assessment of the serum levels of bone alkaline phosphatase with a new immunoradiometric assay in patients with metabolic bone disease. J Clin Endocrinol Metab 1993:77:1046-53.

36 Price PA, Parthemore JG, Deftos U. New biochemical marker for bone metabolism. Measurement by radioimmunoassay of bone GLA protein in the plasma of normal subjects and patients with bone disease. J Clin Invest 1980;66:878-83.

37 Karlsson MK, Johnell O, Obrant KJ. Bone mineral density in weight lifters. Calcif Tissue Int 1993;52:212-5.

38 Maimoun L, Lumbroso S, Manetta J, et al. Testosterone is significantly reduced in endurance athletes without impact on bone mineral density. Horm Res 2003;59:285-92

39 Marino GW, Leavitt JL. Ground reaction forces in the walking patterns of the older adults. In: Jonsson B, ed. Biomecanics X-A. Champaign, IL: Human Kinetics, 1987:413-7.

40 Virtanen P, Viitasalo JT, Vuori J, et al. Effect of concentric exercise on serum muscle and collagen markers. J Appl Physiol 1993;75:1272-7.

41 Welsh L, Rutherford OM, James I, et al. The acute effects of exercise on bone turnover. Int J Sports Med 1997:18:247-51.

42 Salvesen H, Piehl-Aulin K, Liunghall S. Changes in levels of the carboxyterminal propeptide of type I procollagen, the carboxyterminal crosslinked telopeptide of type I collagen and osteocalcin in response to exercise in well-trained men and women. Scand J Med Sci Sports Exerc 1994;4:186-90.

43 Frost HM. Why do bone strength and "mass" in aging adults become unresponsive to vigorous exercise? Insights of the Utah paradigm. J Bone Miner Metab 1999;17:90-7.

\section{Call for papers}

11 th European Forum on Quality Improvement in Health Care 26-28 April 2006, Prague, Czech Republic

Deadline 30 September 2005

For further information and to submit online go to: www.quality.bmipg.com 